\title{
The First-Year Follow-Up of a Cleft Lip and Palate Patient Treated With Nasoalveolar Molding (NAM)
}

Nathália Viegas de Oliveira' ${ }^{\circledR}$, Gabriel Antônio Anjos Tou²@, Raquel Souto Silva ${ }^{1}{ }^{\circ}$, Sérgio Edriane Rezende, ${ }^{3,4}{ }^{\circledR}$, Henrique Pretti ${ }^{2}{ }^{\circledR}$, Soraia Macari²@
The objectives of pre-surgical orthopedics are to allow surgical repair with minimal tension of the involved tissues and less restriction to the craniofacial growth. The aim of this study was to evaluate the benefits of nasoalveolar model (NAM) as a pre-operative therapy in a patient with bilateral cleft lip and palate followed by labioplasty and palatoplasty. A 15-day-old patient underwent orthopedic treatment with NAM. After pre-operative treatment, retraction of the pre-maxilla was observed with reduction of the fissure. Due to the successful effects of NAM treatment the patient had a one-step surgery for lip correction. Six months later, due to lip pressure the fissure was further decreased. After six months, the patient underwent palatoplasty. Both surgeries contributed to the remaining closure of the fissure, which were reduced by half compared to the end of pre-operative treatment. The uses of NAM as a pre-operative treatment approached the alveolar segments, centralized the pre-maxilla, decreased the cleft palate resulting in a marked improvement of the arch and provide superior surgical results. In addition, it allows the primary repair of the patient's lip with asymmetric bilateral fissure in only one-step surgery; in consequence, it will reduce treatment morbidity and decrease cost of treatment.

\author{
'Department of Pediatric Dentistry \\ and Orthodontics, UFMG - \\ Universidade Federal de Minas \\ Gerais, Belo Horizonte, MG, Brazil \\ ${ }^{2}$ Department of Restorative Dentistry, \\ Faculty of Dentistry, UFMG - \\ Universidade Federal de Minas \\ Gerais, Belo Horizonte, MG, Brazil \\ ${ }^{3}$ Department of Head and Neck \\ Surgeon and Skull-Maxillofacial \\ Surgeon, UFMG - Universidade \\ Federal de Minas Gerais, Belo \\ Horizonte, MG, Brazil \\ ${ }^{4}$ Serviço de Cirurgia Plástica \\ - CENTRARE - Hospital da BALEIA, \\ Belo Horizonte, MG, Brazil
}

Correspondence: Soraia Macari, Avenida Presidente Antônio Carlos 6627, 31270-901 Belo Horizonte, MG, Brasil. Tel: +55-31-3409-9660 e-mail: soraiamacari@gmail.com

Key Words: nasoalveolar molding, cleft lip and palate, labioplasty, palatoplasty.

\section{Introduction}

The protocol for the treatment of cleft lip and palate is considered a challenge in dentistry (1), the approach consists of the use of the nasoalveolar molding (NAM) proposed by Grayson et al. (2). The treatment with NAM preceding the surgical intervention is used to nasal cartilages reposition, to approach the alveolar processes, centralize the pre-maxilla, and to elongate the deficient columella $(3,4)$. Cleft lip and palate may be unilateral or bilateral (5). In the bilateral cleft deformity the lower lateral cartilages fails to migrate up into the nasal tip to stretch the columella. The prolabium is positioned directly on the end of the shortened columella. The alar cartilages are positioned along the alar margins and pre-maxilla is suspended from the tip of the nasal septum, whereas the lateral alveolar segments remains behind it (6).

The surgical repair of bilateral cleft lip and palate deformity presents additional challenges for satisfactory results (7), especially when it is accompanied by asymmetry of the alveolar and palate segments with the displaced and projected pre-maxilla (8). During treatment, bilateral cleft lip repair can be performed in one or two stages (8-10); and in cases of asymmetric or incomplete bilateral cleft with displaced or severely projected pre-maxilla, short or absent columella, two-stage lip closure is more feasible $(7,10,11)$. The purpose of pre-surgical orthopedics is to reduce the width of cleft, to obtain the alignment of the segments before the labioplasty allowing the surgical repair with minimum tension, to improve the shape of the arch and to normalize the swallowing pattern avoiding the dorsal positioning of the tongue in the cleft $(3,7,12)$.

Considering that the NAM technique has been shown to significantly improve the surgical outcome of the primary repair in cleft lip and palate patients compared to other techniques of pre-surgical orthopaedics (7), the objective of this article is to show the progress of the pre-operative treatment with the use of NAM and its contribution for the accomplishment of labioplasty in only one-stage surgical time followed by the palatoplasty in a patient with complete bilateral lip and palate cleft using a clinical case report.

\section{Case Report \\ Diagnosis and Etiology}

A male child, 15-old-day patient was referred to an orthodontic evaluation to facilitate the surgical repair of the lip and cleft palate. The patient had a complete bilateral incisive trans-foramen lip and cleft palate with pre-maxilla shifted to left (Fig. 1).According to the mother's report, the complete cleft palate was confirmed at the end of the pregnancy.

The initial impression of the maxilla was made to fabricate the NAM conventional molding plate (Fig. 2). The casts obtained during the follow-up treatment were used to measure the width of the cleft, the length of the arch 
and the distance between the alveolar segments (Fig. 3). The outermost portion of each segment was identified by letters as shown in Figure 3. The cleft was measured by the distance from the mesial segment of the maxillary arch to the distal
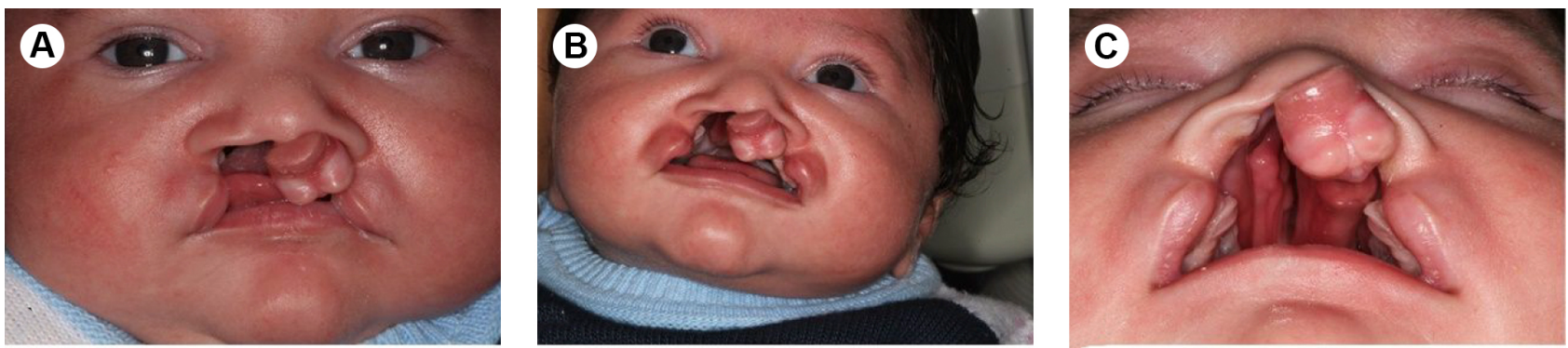

Figure 1. A male child, 15-old-day had a complete bilateral incisive trans-foramen lip and cleft palate with premaxilla shifted to left.
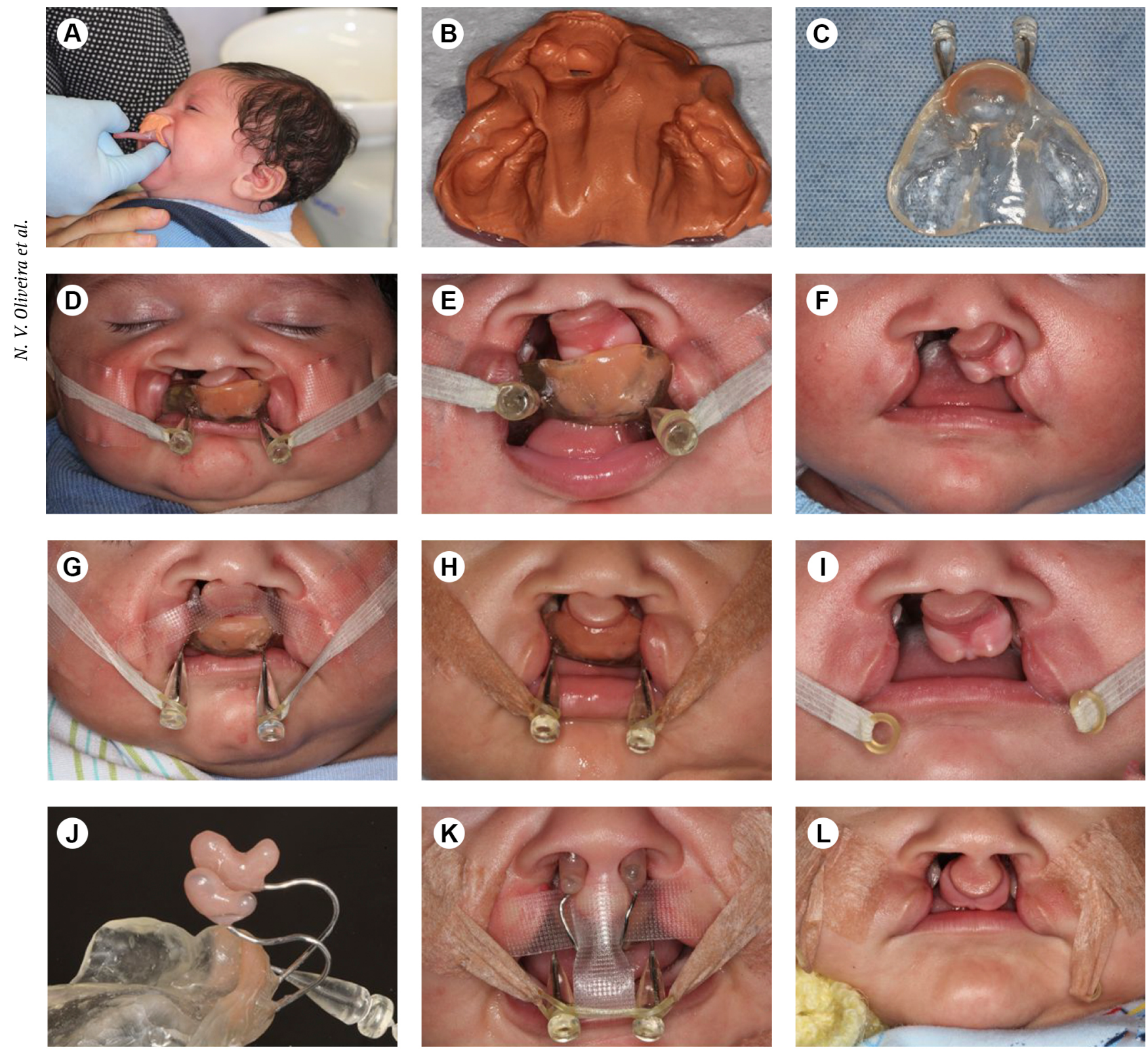

Figure 2. Sequence of treatment with the use of the nasoalveolar molding NAM. 
part of the pre-maxilla segment bilaterally. The width of the alveolar ach was analyzed what was equivalent to the canine (anterior arch width A-D), first (middle palatal arch width E-F) and second molars distance (posterior palatal arch width G-H). Additionally the length of the arch was represented by the I-J line (Fig. 3). The values of the measurements are showed in Table 1. From these measurements it was verified that the pre-maxilla was protruded and decentralized compared to the alveolar segments (Fig. 1).

\section{Treatment Objectives}

The treatment objectives were to redirect the premaxilla to the center of the arch using an orthopedic device nasoalveolar molding (NAM) and to align and approximate the maxillary alveolar segments, and also to elongate the columella pre-operatively and therefore facilitate labioplasty repair within not in two, but in only one-stage surgical time. In addition, this treatment also aimed to reduce the tension in the soft tissues and muscle sutures involved to favor the prognosis of palatoplasty.

\section{Treatment Progress}

The treatment was performed in several stages: (A) pre-operative orthopedics using the NAM fifteen days post-birth, (B) labioplasty surgery three months post-birth, and (C) palatoplasty surgery sixteen months post-birth.

Intraoral maxillary impressions were made using heavy bodied impression material (Express XT ESPE, Unitek/3M, CA, USA) and casts were made from dental stone to prepare the diagnosis and working cast (Fig. 2). The conventional custom molding plate was provided using acrylic resin (JET Clássico, Paulista, SP, Brazil) (3) (Fig. 2). External forces were applied to the plate to retract and centralize the pre-maxilla (9) by an elastic band (tape Elastic Intraoral Latex 3/16 - Morelli, Sorocaba, SP, Brazil) attached to a custom-fitted head cap (Fig. 2). Furthermore, to facilitate the lip repair and balanced orofacial growth hypoallergenic adhesive tapes (Micropore surgical tape; 3M, St Paul, MN) were placed by parents on the lip segments to adduct the lip segments and also to narrow the alar base of the cleft segment $(7,13)$ (Fig. 2). Parents were advised to use NAM $24 \mathrm{~h}$ a day, 7 days a week, in addition to a brief period of cleaning the device twice a day.

During each return visit, selective internal wear on the appliance was made as necessary to move the alveolar segments to the desired area to reduce the distance
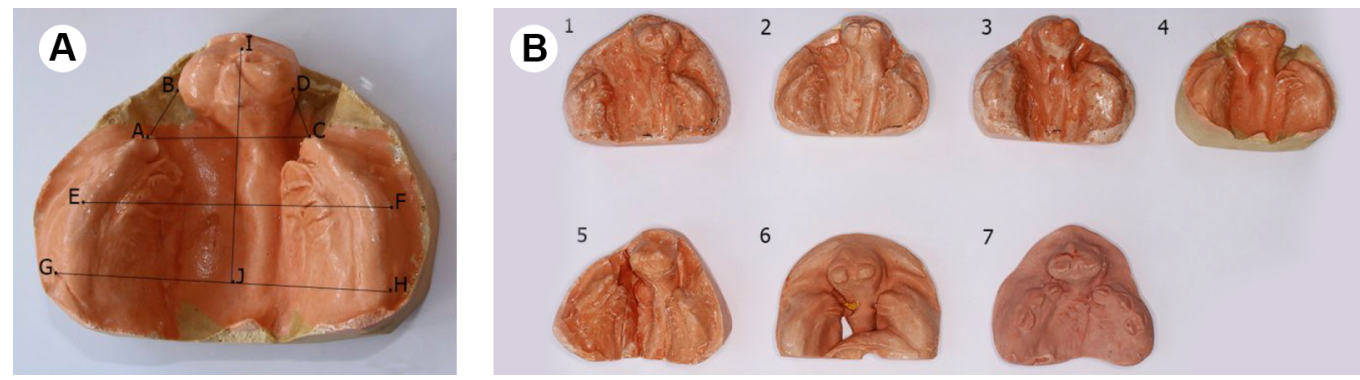

Figure 3. Marking of the outermost points in each anterior, middle and posterior segment of the arch and width of the clefts and registered patient models throughout preoperative and post-operative treatment.

Table 1. Alveolar cleft and alveolar arch measurements in millimeters (mm) within the different treatment phases

\begin{tabular}{|c|c|c|c|c|c|c|}
\hline \multirow{3}{*}{ Stone plaster casts } & $\begin{array}{l}\text { Alveolar cleft } \\
\text { in right side }\end{array}$ & $\begin{array}{l}\text { Alveolar cleft } \\
\text { in left side }\end{array}$ & $\begin{array}{l}\text { Anterior } \\
\text { arch width }\end{array}$ & $\begin{array}{l}\text { Mid palatal } \\
\text { arch width }\end{array}$ & $\begin{array}{l}\text { Posterior } \\
\text { arch width }\end{array}$ & Arch length \\
\hline & A-B & C-D & A-D & E-F & G-H & I-J \\
\hline & \multicolumn{6}{|c|}{$\mathrm{mm}$} \\
\hline 1. Initial & 14 & 10 & 24 & 50 & 48 & 29 \\
\hline 2. Fifiteen days after NAM's use & 11 & 9 & 23 & 50 & 47 & 29 \\
\hline 3. One month afer NAM's use & 10 & 7 & 21 & 50 & 46 & 28 \\
\hline 4. Two month after NAM's use & 6 & 7 & 21 & 50 & 46 & 27 \\
\hline 5. Pre-surgery & 5 & 6 & 21 & 50 & 46 & 26 \\
\hline 6. After labioplasty & 3 & 4 & 16 & 50 & 49 & 22 \\
\hline 7. After palatoplasty & 2 & 3 & 10 & 48 & 51 & 22 \\
\hline
\end{tabular}


between the segments and to produce better contour to the alveolar arch. After the alveolar gap was reduced, the nasal stent was bent at the end of a 0.032-in stainless steel wire that was embedded into the anterior portion of the alveolar molding plate (5). An acrylic extension that pushes the nostrils upward against a counterforce of soft material across the nasolabial junction and stretches the diminutive columella $(2,3,14)$ was added (Fig. 2). The follow-up treatment was made by new impressions that were made during the appointments (Fig. 3).

The active participation of parents and their ability to follow the instructions of home care was fundamental to the therapy. Appointments were scheduled at intervals of one week initially and later there was a two week (5) space.

Subsequently, after three months of intensive use of NAM, the patient underwent the labioplasty (Hospital of Baleia, CENTRARE, Belo Horizonte, MG, Brazil). Firstly, the distance between the outermost region of the pre-maxilla and the bilateral alveolar segments was measured before the incision to determine the extent of detachment of the involved tissues (Fig. 4). The Mulliken technique (9) was used by the surgeon, as a one-step technique, and the cutaneous incisions were then performed to simulate the lip

interrupting or reducing nasal buccal communication in the anterior region (Fig. 4). The orbicularis muscle strap was made in the pre-maxilla by a pressure favoring its retro position (Fig. 4).

Primary palatoplasty determines the prognosis of a patient, and an optimal surgical design should functionally restore functions, including speech, chewing, breathing and aesthetics, while at the same time preserving the normal growth potential in the involved area (15). The patient underwent palatoplasty (Hospital of Baleia, CENTRARE, Belo Horizonte, MG, Brazil) using the Veau-Wardil-Kikner technique when he completed one year and four months of age (Fig. 5) by the same team of surgeons who performed the labioplasty.

\section{Treatment Results}

At the end of the pre-operative treatment a reduction of $3 \mathrm{~mm}$ in the length of the arch was observed with the retraction of the pre-maxilla. There was a reduction of 8 $\mathrm{mm}$ from the right side fissure and $4 \mathrm{~mm}$ from the left side fissure due to the centralization of the pre-maxilla (Fig. 3 model 5).The decrease in arch width was $3 \mathrm{~mm}$ in anterior part of palate and $2 \mathrm{~mm}$ in posterior part (Table 1, model 5). The pre-maxilla was retracted by using the molding plate in conjunction with external tape and elastics (Fig. 2).

Two impressions were made for post-surgical measurements (Fig. 3 models 6 and 7). After three months of intensive treatment with NAM, the patient underwent labioplasty. Six months later, a significant reduction of cleft palate was measured in the plaster model and was compared with the initial model. As shown in Table 1, model 6, the pre-maxilla was retracted $7 \mathrm{~mm}$ and shifted to the right side by $11 \mathrm{~mm}$ after labioplasty. In this same period, the only decrease in arch width was $2 \mathrm{~mm}$ in mid palatal part.

After six months of palatoplasty, a new cast was analyzed (Fig. 3 model 7). Comparing these results and the model performed six months after the labioplasty (Fig. 3, model 7 compared to model 6), any changes where seen
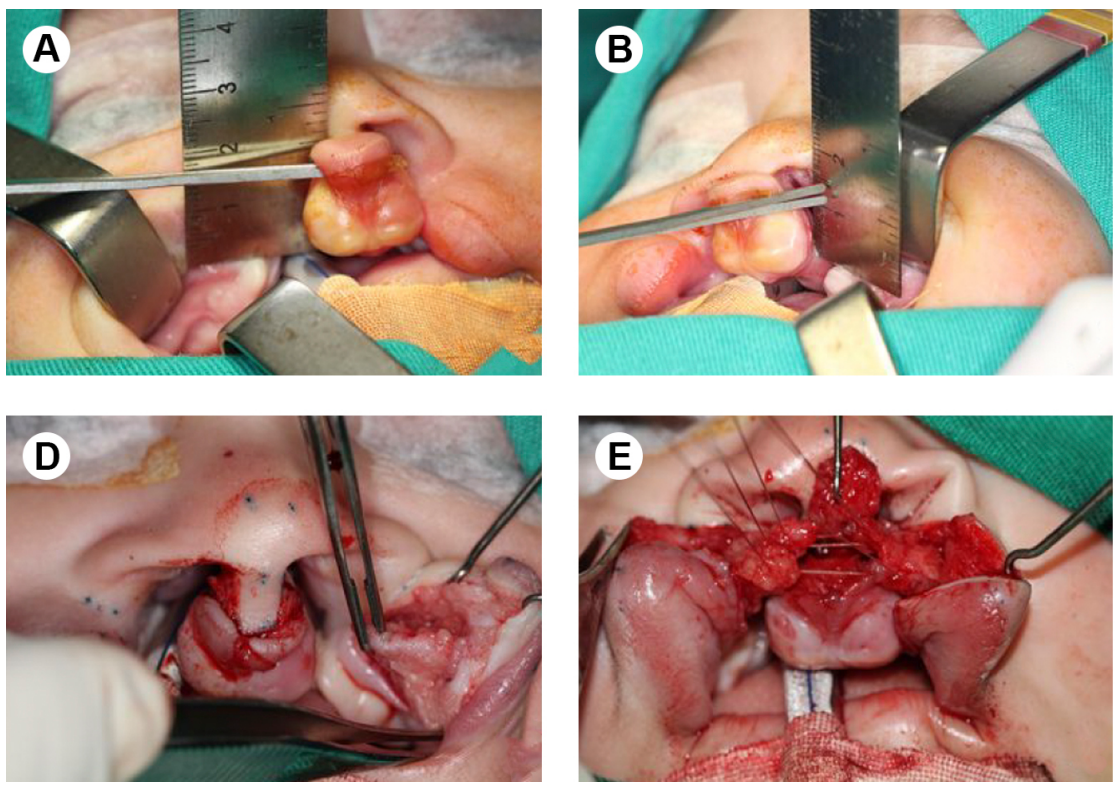
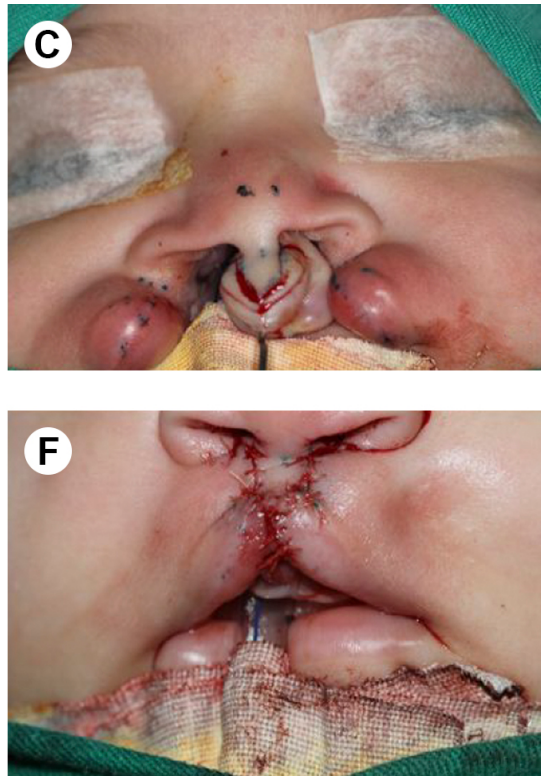

Figure 4. Primary surgery labioplasty 
in arch length. In despite of this, a significant decrease of $6 \mathrm{~mm}$ was observed in the anterior part of the arch resulting from the closure of the palate and $2 \mathrm{~mm}$ in the middle part by traction of the tissues after surgery. There was a $2 \mathrm{~mm}$ increase in the width in the posterior part of the arch by the growth of skeletal structures. In addition, there was a reduction of $1 \mathrm{~mm}$ on both sides of clefts (Table 1). This shows that both labioplasty and palatoplasty surgeries contributed to closure of clefts (Fig. 5 and Table 1). Measurements after the palatoplasty show a reduction
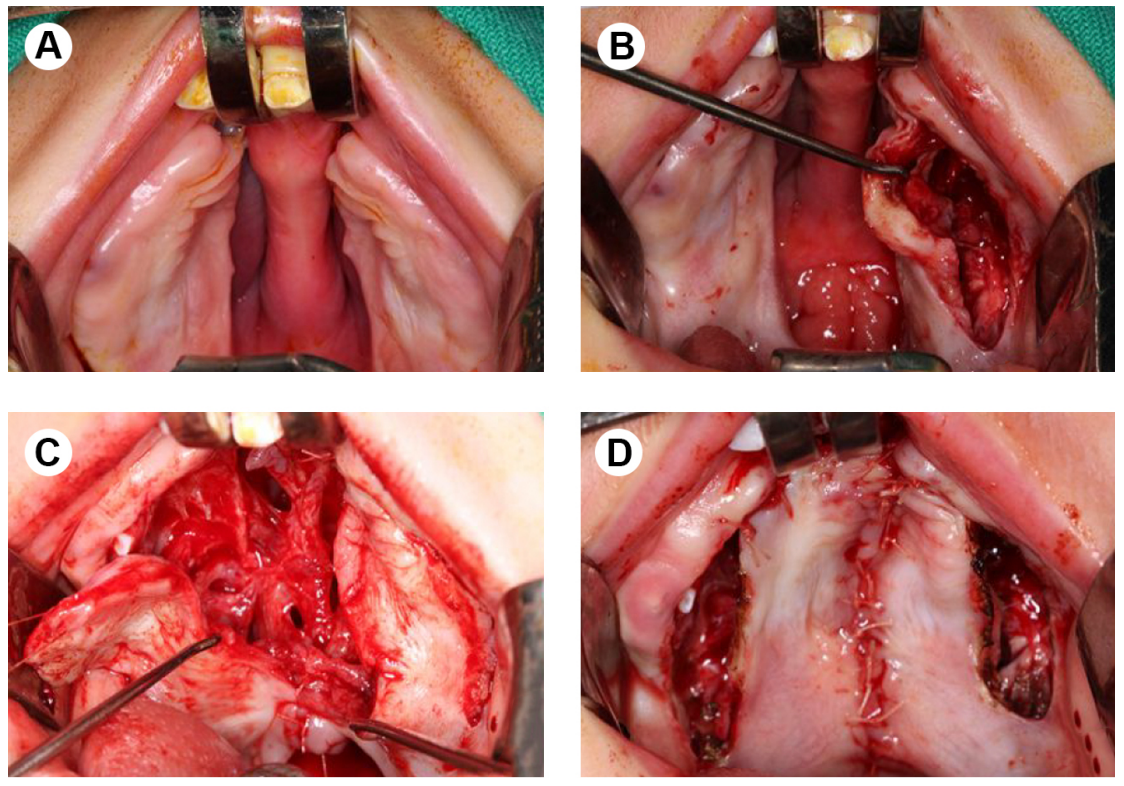

Figure 5. Primary surgery palatoplasty


Figure 6. Pretreatment, post-treatment pre-operatory, one month after labioplasty and one month after palatoplasty, respectively on the cleft in half when comparing to the model after the pre-operative treatment (Table 1 and Fig. 3 model 7 compared to model 5).

\section{Discussion}

Treatment of patients with cleft lip and palate may combine surgery and orthopedics. The orthopedic treatment of patient described in our study started 15 days post birth. The patient presented a complete bilateral trans-forame lip and palate cleft and pre-maxilla displaced to the left. Alveolar gap bilateral were $14 \mathrm{~mm}$ and $10 \mathrm{~mm}$ successively. In view of these conditions, the nasal alveolar molding was used until the period of labioplasty. After orthopedic treatment, there was a centralization of the pre-maxilla and reduction of the clefts due to the approximation of the alveolar segments obtained by the use of NAM. Because of the good results, the surgical correction of the lip was made in only one surgery, unlike what is proposed by some authors regarding the severity of the initial case $(8,10)$.

The practice of NAM offers some significant benefits to the patient. The objectives of NAM, as described by many authors (1$4,7,12,14,16)\{$ Punga, $2013 \# 164\}$ are to provide symmetry to severely deformed nasal cartilages, to achieve projection of the flattened nasal tip, to provide nonsurgical elongation of the columella, to improve alignment of the alveolar ridges, and to reduce the distance between the cleft lip segments. NAM can be applied to the entire range of cleft deformities, including complete clefts without an intact nasal floor (5) in corroboration with our case.

Several pre-surgical infant orthopedics techniques have been described, such as lip taping. This technique is a nonsurgical method of mobilizing and graft on the soft tissues of the lip, nose, and maxilla before primary cleft lip repair (17). It is a widely used method, but is 
a complementary technique to NAM therapy. Another alternative to the treatment is pre-directional appliance (16) which is the modification of Grayson's pre-surgical nasoalveolar molding. This technique has presented excellent results in a case report that the pre-maxilla was shifted to the left side by $5.5 \mathrm{~mm}$ in one patient with bilateral fissure and projected pre-maxilla asymmetry (16). This finding is compatible with our study, which also showed success in the centralization of the maxilla through the approximation of the segments, with a $7 \mathrm{~mm}$ retraction of the pre-maxilla and was displaced to the right side in $11 \mathrm{~mm}$.

As shown in the present case report, excellent results were obtained in the approximation of the alveolar segments and in the centralization of pre-maxilla. This can be explained by the wearing of the acrylic in the direction of the desired movement and the addition of acrylic resin in the space of the pre-maxilla similarly proposed by Grayson (2). However, there was little improvement in the elongation of the columella. This may be justified by delayed activation of nasal stents.

The correction of the cleft nasal deformity is a great esthetic challenge to the orthodontist. The patient has used a conventional stent incorporated in the appliance when the alveolar cleft gap was reduced. Subramanian et al (4) modified the NAM device by making the nasal stent with titanium molybdenum alloy (TMA) wire. The advantage of the TMA wire is that it is more resilient, and hence, activation can be done once in 2 weeks. But this technique is appropriate only for unilateral cleft palate. Matsuo et al. (18) reported that cartilage alar is more malleable to the orthopedic maneuver soon after birth, a result of elevated levels of maternal estrogen circulating in the child's bloodstream and sialuronic acid levels in the nasal cartilage. We must take advantage of the plasticity of the infant cartilage, whereas at three months of age a reduction of this plasticity occurs. Through this, the authors declare pre-operative non-surgical correction should therefore begin as soon as possible $(19,20)$ to promote permanent correction in its form (3).

Lip taping or surgical lip adhesion as alone procedures can be a disadvantage for bilateral cleft lip and palate patients. If the control of the alveolar segments is not achieved, the pre-maxilla can descend vertically, and the anterior aspect of the posterior alveolar segments can collapse palatally (5). The lip taping is a simple inexpensively technique. It is applied on the lip along the cleft just after birth to reshape and approach the alveolar arch (17) and in our study it was used as auxiliary therapy to NAM (3). Also, the purpose of the use of facial adhesive tape associated with elastic was to assist in the fixation of NAM on the face of the baby and to press

re-operative treatment with the NAM seems to be fundamental for better post -surgical results (21-24). That was shown not only in the present case report but also in a comparative study where patients who were treated with NAM obtained better aesthetic and functional results (20).

As previously reported, early cleft care using NAM are clearly described on the literature (13). There is no doubt about the gains made by pre-operative orthopedics (13). However, parental collaboration was the main factor that contributed to the success of the treatment. The birth of a child with a fissure can be traumatic and challenging for the family due to severe distortion of the nose, lip and maxillary arch (5). Therefore, the orthodontist should encourage parents during each visit to use NAM in so that the gains are compatible with the expected result.

The use of NAM as a pre-operative treatment approached the alveolar segments, centralized the premaxilla, and decreased the cleft palate resulting in a marked improvement of the arch. In addition, it allows the primary repair of the patient's lip with asymmetric bilateral fissure in only one-step surgery in consequence it will reduce treatment morbidity, decrease cost and provide better results during primary repair.

\section{Resumo}

Os objetivos da ortopedia pré-cirúrgica são permitir a correção cirúrgica com minima tensão dos tecidos envolvidos e menor restrição ao crescimento craniofacial. 0 objetivo deste estudo foi avaliar os benefícios do modelo nasoalveolar (NAM) como terapia pré-operatória em um paciente com fissura labiopalatina bilateral seguida de labioplastia e palatoplastia. Um paciente de 15 dias de idade foi submetido a tratamento ortopédico com NAM. Após o tratamento pré-operatório, observou-se retração da pré-maxila com redução da fissura. Devido aos efeitos bem-sucedidos do tratamento com NAM, o paciente realizou a cirurgia em um único tempo cirúrgico para correção dos lábios. Seis meses após verificou-se a continuidade da redução da fissura devido à pressão labial. Após dozes meses, o paciente foi submetido à palatoplastia. Ambas as cirurgias contribuiram para o fechamento remanescente da fissura, que foram reduzidas pela metade em comparação com o final do tratamento préoperatório. 0 uso do NAM como tratamento pré-operatório proporcionou a aproximação dos segmentos alveolares, centralização da pré-maxila, diminuição da fissura palatina, resultando em melhora acentuada do arco, resultando em procedimentos cirúrgicos mais eficazes. Além disso, permitiu o reparo primário do lábio do paciente com fissura bilateral assimétrica em apenas uma cirurgia; em conseqüência, reduzindo a morbidade do tratamento e diminuição dos custos do tratamento.

\section{Acknowledgements}

Personal sources of funding were used in this case report.

\section{References}

1. Erüz $M$, Yagci $A$, Ozyazgan I. A new technique for retracting the protrusive premaxilla with fewer patient visits. Cleft Palate Craniofac J 2019;4:543-547.

2. Grayson BH, Cutting $\mathrm{C}$, Wood R. Preoperative columella lengthening in bilateral cleft lip and palate. Plast Reconstr Surg 1993;92:1422-1423.

3. Grayson $B H$, Santiago $P E$, Brecht LE, Cutting CB. Presurgical nasoalveolar molding in infants with cleft lip and palate. Cleft Palate Craniofac J 1999;36:486-498.

4. Subramanian CS, Prasad NKKK, Chitharanjan AB, Liou EJW. A modified 
presurgical orthopedic (nasoalveolar molding) device in the treatment of unilateral cleft lip and palate. Eur J Dent 2016;10:435-438.

5. Grayson BH, Garfinkle JS. Early cleft management: the case for nasoalveolar molding. Am J Orthod Dentofacial Orthop 2014;145:134142.

6. Millard DR Jr. Embryonic rationale for the primary correction of classical congenital clefts of the lip and palate. Ann R Coll Surg Engl 1994;76:150-160.

7. Grayson BH, Cutting CB. Presurgical nasoalveolar orthopedic molding in primary correction of the nose, lip, and alveolus of infants born with unilateral and bilateral clefts. Cleft Palate Craniofac J 2001;38:193198.

8. $\mathrm{Xu} \mathrm{H}$, Salyer KE, Genecov ER. Primary bilateral two-stage cleft lip/nose repair: part II, J Craniofac Surg 2009;20:1927-1933.

9. Mulliken JB. Repair of bilateral cleft lip and its variants. Indian J Plast Surg 2009;42:S79-90.

10. $\mathrm{Xu} \mathrm{H}$, Salyer KE, Genecov ER. Primary bilateral one-stage cleft lip/ nose repair: 40-year Dallas experience: part I. J Craniofac Surg 2009;20:S1913-1926.

11. Chung KH, Lo L. One-stage vs. two-stage repair of asymmetric bilateral cleft lip: a 20-year retrospective study of clinical outcome. Plast Reconstr Surg 2018;141:1215-1224.

12. Maull DJ, Grayson BH, Cutting CB, Brecht LL, Bookstein FL, Khorrambadi $D$, et al. Long-term effects of nasoalveolar molding on threedimensional nasal shape in unilateral clefts. Cleft Palate Craniofac J 1999;36:391-397.

13. Isik Aslan B, Gülşen A, Findikçioğlu K, Uzuner D, Üçüncü N. effects of nasoalveolar molding therapy on alveolar and palatal cleft deformities in unilateral and bilateral cleft lip and palate. J Craniofac Surg 2018;29:e179-e184.

14. Punga R, Sharma SM Sharma. Presurgical orthopaedic nasoalveolar molding in cleft lip and palate infants: a comparative evaluation of cases done with and without nasal stents. J Maxillofac Oral Surg 2013;12:273-288.
15. Shi B, Losee JE. The impact of cleft lip and palate repair on maxillofacial growth. Int J Oral Sci 2015;7:14-17.

16. Daigavane PS, Hazarey $\mathrm{P}$, Vasant $\mathrm{R}$, Thombare R. Thombare. Predirectional appliance: a new approach to correct shifted premaxilla in bilateral cleft cases. J Indian Soc Pedod Prev Dent 2011;29:S39-43.

17. Pool R, Farnworth TK. Preoperative lip taping in the cleft lip. Ann Plast Surg 1994;32:243-249.

18. Matsuo K, Hirose T, Tomono T, Iwasawa M, Katohda S, Takahashi N, et al. Nonsurgical correction of congenital auricular deformities in the early neonate: a preliminary report. Plast Reconstr Surg 1984;73:38-51.

19. Matsuo $K$, Hirose T. Preoperative non-surgical over-correction of cleft lip nasal deformity. Br J Plast Surg 1991;44:5-11.

20. Kalantar-Hormozi, Ghalambor A, Tolouei M. Investigating the surgical outcomes of Nasoalveolar Molding (NAM) approach in cleft lip and palate repairing operations. Int J Pharm Res Allied Sci 2016;5:412-416.

21. Patel PA, Rubin MS, Clouston $S$, Lalezaradeh $F$, Brecht $L E$, Cutting $C B$, et al. Grayson. comparative study of early secondary nasal revisions and costs in patients with clefts treated with and without nasoalveolar molding. J Craniofac Surg 2015;26:1229-1233.

22. Yu $Q$, Gong $X$, Shen G. CAD presurgical nasoalveolar molding effects on the maxillary morphology in infants with UCLP. Oral Surg Oral Med Oral Pathol Oral Radiol 2013;116:418-426.

23. Shetty V, Vyas HJ, Sharma SM, Sailer HF. A comparison of results using nasoalveolar moulding in cleft infants treated within 1 month of life versus those treated after this period: development of a new protocol. Int J Oral Maxillofac Surg 2012;41:28-36.

24. Liang Z, Yao J, Chen PKT, Zheng C, Yang J. Yang. Effect of presurgical nasoalveolar molding on nasal symmetry in unilateral complete cleft lip/palate patients after primary cheiloplasty without concomitant nasal cartilage dissection: early childhood evaluation. Cleft Palate Craniofac J 2018;12:2612-2617.

Received July 3, 2019

Accepted November 27, 2019 